\title{
Spatio-temporal analysis of road traffic accidents in Indian large cities
}

\author{
Dinabandhu Mahata ${ }^{\mathrm{a}}$, Pralip Kumar Narzary ${ }^{\mathrm{b}, *}$, Dipti Govil ${ }^{\mathrm{b}}$ \\ ${ }^{a}$ School of Earth Sciences, Department of Geography, Neelakudi Campus, Kangalancherry, Central University of Tamil Nadu, Thiruvarur, 610005, Tamil Nadu, India \\ ${ }^{\mathrm{b}}$ International Institute for Population Sciences (IIPS), Govandi Station Road, Deonar, Mumbai, 4000 88, India
}

A R T I C L E I N F O

\section{Keywords:}

Road traffic accident

India

Urban areas

Health threat

Spatio-temporal

\begin{abstract}
A B S T R A C T
Introduction: Every day 1374 road traffic accidents (RTAs) and 400 deaths take place in India. The number of deaths in RTAs would increase to 662 persons per day in 2030 and will not begin to decline until 2042, which is a serious public health concern.

Objectives: Present paper attempts to analyse the trends and patterns of RTAs in India during the year 2000-2015, and the patterns in the year 2015 in cities with population size 2 million or more.

Methods: Three years moving average is calculated to nullify the fluctuations in the data, exponential curve drawn to assess the pattern. Simple growth rate is calculated and absolute change found out to assess the difference between the year 2000 and 2015.

Results: The exponential growth rate curve of the number of RTAs shows upward trend during 2000-2015 in India. The spatial analysis of severity shows that there is no direct link between the number of accidents and the severity. The city-wise analysis of RTAs by the vehicle involved, age of the persons, cite, and timing of accidents shows a varying pattern across the cities.

Conclusions: The results suggest for city-based strategies to reduce the RTAs, injuries, and deaths, under the umbrella of national policy.
\end{abstract}

\section{Introduction}

The road traffic accidents (RTAs) are concerning issues in public health owing to the increasing number of motor vehicles around the world. According to Global Status Report 2015, more than 1.2 million people die each year on the roads of the world, and 50 million suffer non-fatal injuries. ${ }^{1}$ More than 90 per cent of RTAs occur in the low and middle-income countries, though they have only 54 per cent of registered motor vehicles. ${ }^{1}$ In India, 1374 accidents and 400 deaths take place every day, which means on an average about 57 accidents and 17 persons die every hour. ${ }^{2}$ It is estimated that nearly 2,41,751 persons would die due to RTAs in the year 2030, if the scenario remains unchanged and if strong and integrated road safety mechanisms are not put in place. ${ }^{3}$ Further, if the present policies continue, the RTAs death rate in India will not begin to decline until the year 2042. ${ }^{4}$ Globally, RTAs is a leading cause of death among young people, and the main cause of death among the 15-29 years old population. ${ }^{1}$ In India, people of economically active age group, that is $30-59$ years, are most vulnerable. ${ }^{5}$ A study ${ }^{6}$ conducted in Bhubaneswar city showed the involvement of 18-34 years old to be maximum in RTAs. In India, pedestrians, bicyclists and motorcyclists comprise a large proportion of deaths on all types of RTAs. ${ }^{7}$ As such, beyond the enormous suffering they cause, road traffic crashes can drive a family into poverty due to the various expenses involved in it, including the loss of the family breadwinner. ${ }^{8}$ As per a study, most of the victims of RTAs are the breadwinner of the family. ${ }^{9}$ The financial burden, particularly, is high for poorer households in rural areas, and those seeking treatment at private health facilities with no health insurance. ${ }^{10}$ RTAs continue to be a social threat, incurring a heavy loss of valuable human resource. ${ }^{8}$ Thus, it is obvious that RTAs is one of the biggest threats to human life in India ${ }^{11}$ and as such needs deeper understanding.

It is noted that the burden of RTAs is relatively low in million plus cities as compared to rural areas in India. Fatality risk per 100,000 population varies between 3.0 in Kolkata to 25.5 in Jaipur. ${ }^{5}$ But, cities are the foci of all sorts of human activities providing economic opportunities to its inhabitants that attracts rural population in mass. In the urban areas, large proportion of people including migrants from rural areas commute everyday using different modes of transportation (as per their capacity, need, suitability and availability) exposing them to the risk of RTAs. Travel patterns in India present a complex and a unique mix of traffic modes and are going through rapid changes. ${ }^{12}$ Further, like any other country, in India too, the traffic police is the source of official statistics on road traffic deaths. ${ }^{7}$ The statistics available on RTAs is suggested to be underreported. ${ }^{11}, 6$ Additionally, the official

\footnotetext{
* Corresponding author.

E-mail addresses: dinabandhumahata1991@gmail.com (D. Mahata), pralipkn@gmail.com (P.K. Narzary), dgovil@iips.net (D. Govil).
} 
government statistics of road traffic deaths in India also under-represent the number of pedestrians and motorised two-wheeler riders. ${ }^{7}$ Research on RTAs in cities is required to understand the magnitude of the problem and safety features so that it can help to formulate appropriate policies. Hence, the present paper attempts to analyse the trends and patterns of RTAs in India during 2000-2015, and understand the pattern of RTAs in major Indian cities in 2015 .

\section{Methodology}

The Census of India 2011 data shows that about 31 per cent of India's population lives in the urban areas. About 377 million people in India inhabit in 7935 towns/cities. ${ }^{13}$ Since urban centres are quite diverse regarding its population size and other characteristics, covering all centres was cumbersome and somewhat not relevant. As such, the present study considered cities with a population of 2 million and above. There are 13 cities in India which have a population of 2 million and above. To fulfil the first part of the objective, due to the irregularity in the annual data, we have considered times series data from 2000 to 2015 only. Data before the year 2000 is not available on regular interval. Annual data usually suffers from fluctuations. Hence, we have applied three years moving average to nullify the fluctuations in the data, and the result is presented in graphical form. Simple growth rate is calculated and absolute change found out to assess the difference between the year 2000 and 2015. The patterns of RTAs is assessed through the number of fatalities and the severity index. Severity index is the number of deaths per cent accidents in a given year in an urban centre. The percentage of deaths by vehicle is calculated to get an idea of which type of vehicle is more responsible for accidental deaths. The result is presented as a stacked graph out of a hundred accidents. The proportion distribution of deaths by broad age group is computed, and the result is presented as a stacked graph. The percentage distribution of accidents by location and time is presented in tabular form to understand the occurrence of accidents and its association with the type of location and time.

\section{Results}

\subsection{Trends in RTAs in India during 2000-2015}

The number of RTAs in India from 2000 to 2015, its three years moving average and exponential growth rate are presented in Fig. 1. The dashed line in the graph depicts the number of RTAs as per the official statistics, about 391 thousand RTAs occurred in India in the year 2000. Then there is a stable increase in the number of total RTAs from 2000 till 2010. The number touched about 500 thousand mark in the year 2010. The figure slowly started declining from the year 2010 till 2013. In the year 2013, the figure reached to 486 thousand. After that again there was a marginal rise in the figure to cross 500 thousand mark in the year 2015. Overall, there is about a 28 per cent increase in the number of RTAs during the year 2000-2015, which is about 110 thousand increase in absolute term.

The three-year moving average, presented as a dotted line, depicts a slightly smoother trend than the single year data. Throughout the study period, the lines of single year data and three years moving average are very close to each other, this suggests that the available single year data is already pretty smooth. In other words, there is a steady increase in the number of RTAs in India during the study period. Similarly, the exponential growth rate line, presented as a straight line, shows a constant linear rising trend. All the three lines suggest that there is a regular increase in the number of accidents over the last sixteen years.

The total number of persons killed have steadily increased during the study period (Fig. 2). In the year 2000, the number of deaths was almost 80 thousand, and by the year 2015, it has reached to 146 thousand. During the period there is 85 per cent increase in the number of deaths and the absolute number increased by 67 thousand. Similarly, the fatal RTAs in the year 2005 were about 83 thousand and it has reached as high as 131 thousand in the year 2015. There is 58 per cent growth over the decade. Regarding the absolute figure, there is about 48 thousand increase in the number of fatal RTAs.

From the bar graph (Fig. 2) it is evident that there is a similar pattern of steady rise in both the number of fatal accidents and the number of deaths. The severity index is presented as a line graph in the same figure, with its scale on the right vertical axis. The severity of RTAs in India in the year 2000 was about 20 per cent. It means out of hundred accidents, about 20 persons died in the year 2000 . The severity continued to rise till 2011 to reach about 28.6 per cent. But, between the year 2011 and 2012, there is a marginal decline in the severity index. After that, during 2012-2015 there is a marginal increase. By the year 2015, the severity of RTAs in India has reached about 29 per cent. As such, overall there is about 9 per cent point increase in the severity during the study period.

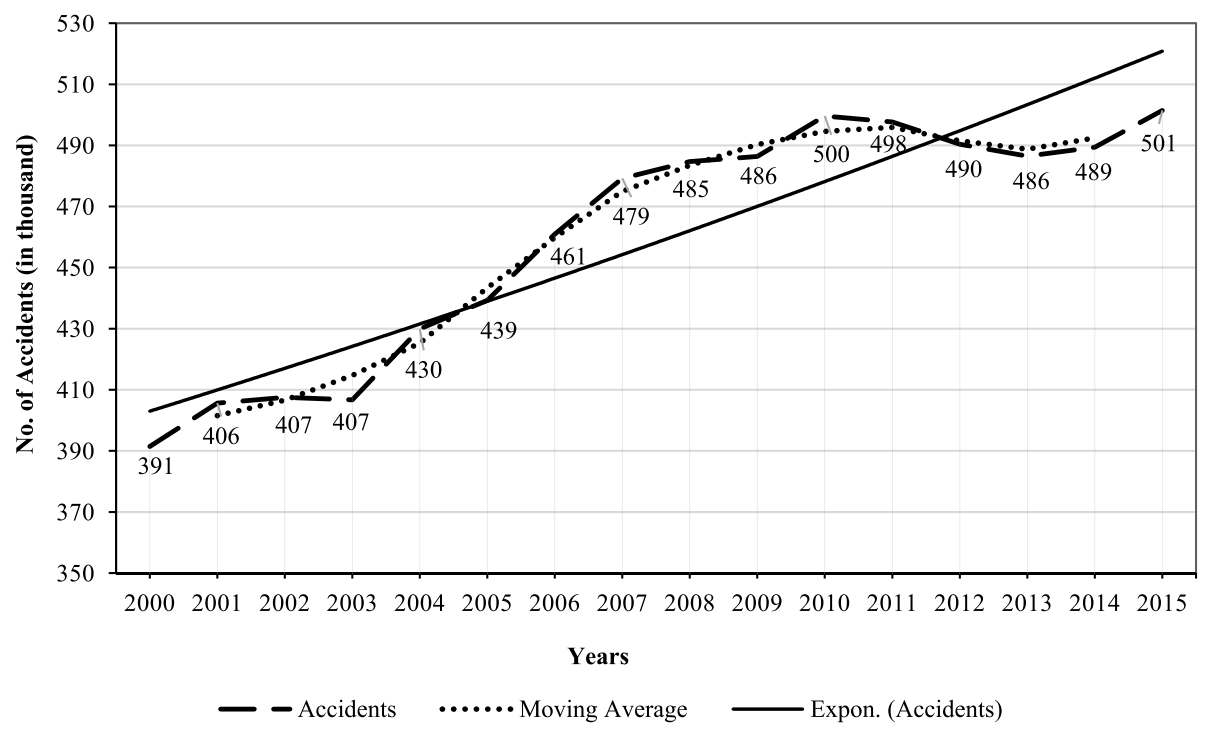

Fig. 1. Trends in Road Traffic Accidents in India during 2000-2015 (in Thousand) Data Source: Ministry of Road Transport and Highway, Govt. of India. (Available at https://www.indiastat.com/table/crime-and-law-data/6/road accidents/17897/ 443689/data.aspx). 


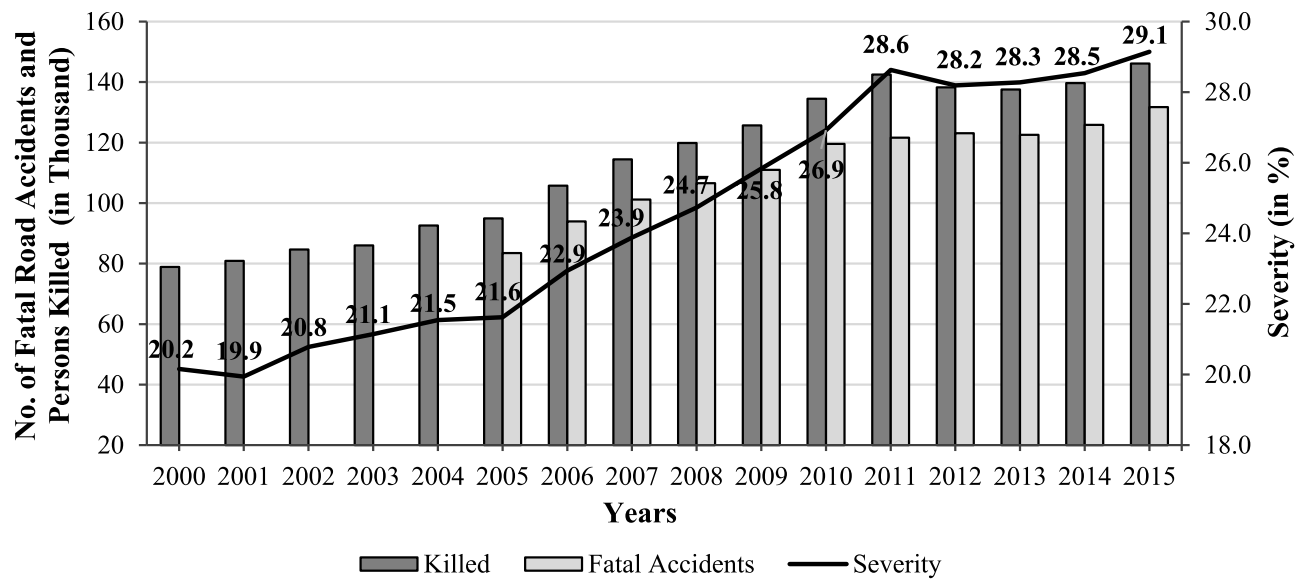

Fig. 2. Number of fatal road accidents and persons killed (in thousand), and severity of road accidents (in \%) in India during 2000-2015

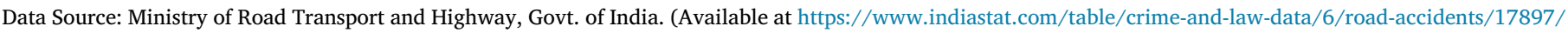
443689/data.aspx).

\subsection{Patterns of RTAs in selected cities}

Citi wise, the persons killed in road accidents, the fatal accidents, and the severity index in 2015 are presented in the Fig. 3 and Map: 1. The graph shows that the number of persons killed and fatal RTAs are maximum in Delhi followed by Chennai. A minute observation of the graph reveals that though the persons killed, and the number of fatal RTAs are comparatively lower in Kanpur among the studied towns, the severity (shown as a solid triangle) is maximum in it. In Kanpur, about 45 per cent of the accidents turned out to be severe. Contrary to this, although the number of RTAs occurred is maximum in Mumbai $(23,468)$, the severity of RTAs is quite negligible Only 2.6 per cent of accidents turn out to be severe in Mumbai. Another apparent pattern of RTAs in large Indian cities is that although the number of RTAs is the lowest in Surat $(903)$ and Nagpur $(1,254)$, the severity of accidents in these cities is somewhat at the higher side.

\subsection{Vehicles involved in RTAs}

The RTAs by type of vehicles in Indian cities in 2015 (in proportion) is presented in Fig. 4 to understand the involvement of different types of vehicle in the RTAs. The graph shows that out of the total thirteen studied cities, except Kolkata and Lucknow, the involvement of twowheelers is maximum. In Hyderabad, the proportion of two-wheelers involved in the RTAs is as high as 65 per cent, and in Pune, it is 48 per cent. However, in Kolkata and Lucknow, the involvement of twowheelers is only 17 and 29 per cent respectively. In three cities, namely Kanpur, Nagpur and Lucknow, the truck is involved in about 31 per cent of the RTAs. Whereas, in Hyderabad (4\%) and Surat (9\%) involvement of truck/lorry is minimal. The proportion of car involved in accidents is about one-fifth of total accidents in Ahmedabad, Delhi, and Mumbai. But, the proportion of involvement of car in RTAs is less than one-tenth in Surat and Chennai. Involvement of bus in RTAs is as high as 19 per cent in Kolkata and 15 per cent in Ahmedabad, whereas it is pretty negligible in Surat $(2 \%)$. The involvement of other vehicles (other than two-wheelers, car, bus, and truck) in RTAs in cities of India is as high as 40 per cent of total accidents in Surat, whereas it is only 10 per cent in Hyderabad and 11 per cent in Pune.

\subsection{Persons involved in RTAs}

The RTAs data is also cross-classified by broad age groups (0-14, $14-30,30-45,45-60$, and 60 and above years), and available for different cities (Table 1). The proportion of persons involved in RTAs is concentrated mainly in the board age group of 14-45 years in all the selected cities. The contribution of this broad age group to total accidents ranges between 58 per cent in Chennai to as high as 86 per cent in Hyderabad. The contribution of age group 30-45 years varies between
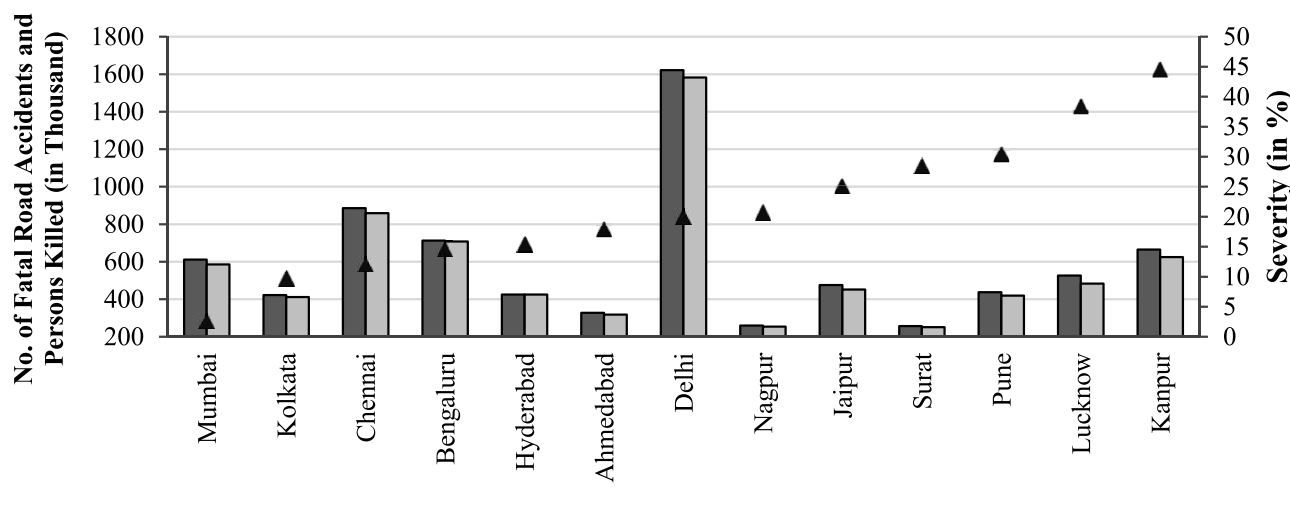

Cities

$\square$ Killed $\quad$ Fatal Accident $\Delta$ Severity

Fig. 3. Number of persons killed, fatal accidents (in thousand) and severity index (in \%) in selected cities of India, 2015.

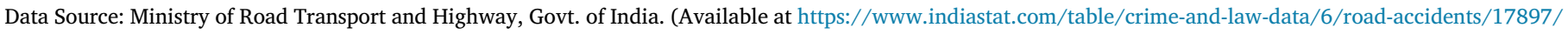
443689/data.aspx). 


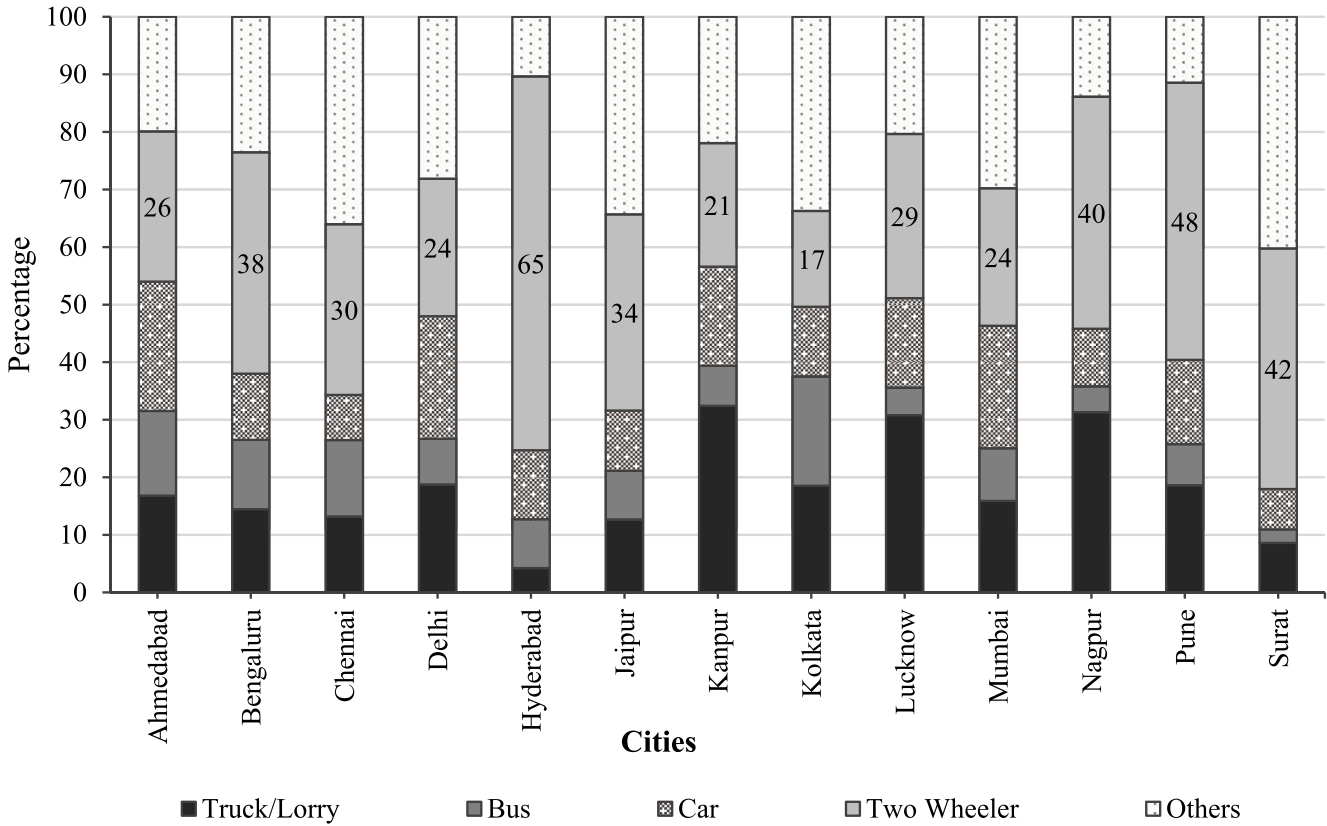

Fig. 4. Percentage distribution of Road Traffic Accidents in Indian cities by type of vehicles, 2015

Note: 'Others' vehicles in Fig. 4 include: (i) SUV/Station Wagon etc, (ii) Jeep, (iii) Tractor, (vi) Three Wheeler/Auto Rickshaw, (v) Other motor vehicles and, (vi) Bi-cycle

Data Source: Ministry of Home Affairs, Govt. of India (Available at https:// www.indiastat.com/table/crime-andlaw-data/6/incidence-of-roadaccidental-deaths-by-type-of-vehicles1991-2017/571571/1034459/data. aspx).
26 per cent in Chennai and Mumbai to 51 per cent in Kolkata. Further, the proportion of persons involved in RTAs for age group 45-60 years is only 10 per cent in Hyderabad and as high as 30 per cent in Kolkata. The contribution of the child population ( $0-14$ years) is quite negligible in almost all the selected cities. The concentration of RTAs among the older age is somewhat tolerable in few cities like Lucknow, Kolkata, Hyderabad, Delhi and Surat. But it is comparatively high in the cities like Pune, Mumbai, Nagpur and Chennai. Thus, there is a diverse pattern in persons involved in the RTAs across different cities of India.

\subsection{RTAs in Indian cities by location}

The RTAs by location are presented in Table 2. As per the classification, RTAs take place mostly near a residential area and at pedestrian crossing points. In Surat, as high as 48 per cent of the total accidents occur near the residential area, but in Chennai, only 2 per cent of accidents occur near a residential area. In Kolkata, almost half (46\%) of the total accidents take place at the pedestrian crossing points. Contrary to this, hardly any accidents occur at pedestrian crossing points in cities like Jaipur, Lucknow, and Kanpur. It is worth mentioning that about one-fifth of the total accidents in Surat takes place near a factory or industrial area. The proportion of accidents taking place near religious place or cinema hall is quite low in all the selected cities of India.

\subsection{RTAs in Indian cities by timing}

As per the classification of the timing of accidents, it is observed that except mid-night to early morning $(0.0-6.0 \mathrm{~h})$, the accidents are somewhat evenly distributed (Table 3 ). However, out of total accidents, the proportion of accidents occurring during $18-21 \mathrm{~h}$ is higher than at other times in almost all the selected cities. In cities like Surat, Nagpur, Jaipur, and Chennai, about one-fifth of the total accidents take place during $18-21 \mathrm{~h}$ of timing. Following this, another time slot is $12-15 \mathrm{~h}$. During this time the proportion of occurrence of accidents is comparatively high in Jaipur (20\%) and Surat (18\%).

\section{Discussion}

RTAs may cause a heavy economic burden on the household due to the loss of a working person, prolonged medical care of the injured person, and taking care of disabled person. This may also have serious social implications. The economic costs also strike hard at a national level, imposing a significant burden on health, insurance, and legal systems. ${ }^{1}$ Sustainable Development Goal 3 aims to ensure healthy lives and promote well-being for all at all ages. Further, it seeks to halve the number of global deaths and injuries from RTAs by 2020. Further, the Sustainable Development Goal 11 aims to make cities and human settlements inclusive, safe, resilient and sustainable. The idea behind this goal is to provide access to safe, affordable, accessible and sustainable transport systems for all by $2030 .{ }^{1}$ In this context, study on trends and patterns of RTA is quite appropriate.

India recorded about 28 per cent growth in total RTAs from 2000 to 2015 and there is no direct link between the number of accidents and the severity of the accidents. It is encouraging to see that this growth from 2005 to 2015 is only about 14 per cent. But the issue of serious concern is that the fatal RTAs have increased by almost 50 per cent. This may have to do more with an increase in the number of high-speed vehicles. Hence, policymakers may also think about implementing demonstrated effective and cost-effective success of automated speed enforcement system to reduce injuries relating to RTAs. However, policy measures found to be effective in one setting may not be suitable for another place, ${ }^{14}$ or even it may not be appropriate at all. Hence, strategies that are found to be successful in curbing the RTA in a cost effective manner may be replicated on pilot basis in the selected cities during the initial phase, later scale up if found successful.

The study shows that in India the distribution of injuries and death rates from road crashes over the years 1999-2001 is highly variable between regions. ${ }^{15}$ Also, analysis of RTAs scenario at the state and city level show a huge variation in fatality risk across states and cities. ${ }^{5}$ Similarly, in the present study, the proportion of different types of vehicles involved in an accident shows that there is no uniform pattern across the cities. This is basically due to the fact that each city has different road built-up, mixture of traffic modes, varying weather conditions, functions, population composition etc. For example, in terms of temperature, Mumbai has very nominal seasonal variation, whereas Delhi has extreme seasonal variation. It is also notable that though the persons involved in RTA is mainly from the broad economically active population, yet there are differences across the different cities. This variation may be due to the differences in proximity between the residence and the work place, or educational institution etc. It is also noteworthy that the RTAs do not occur in similar places across the cities, nor during the similar time. The road structure and the 


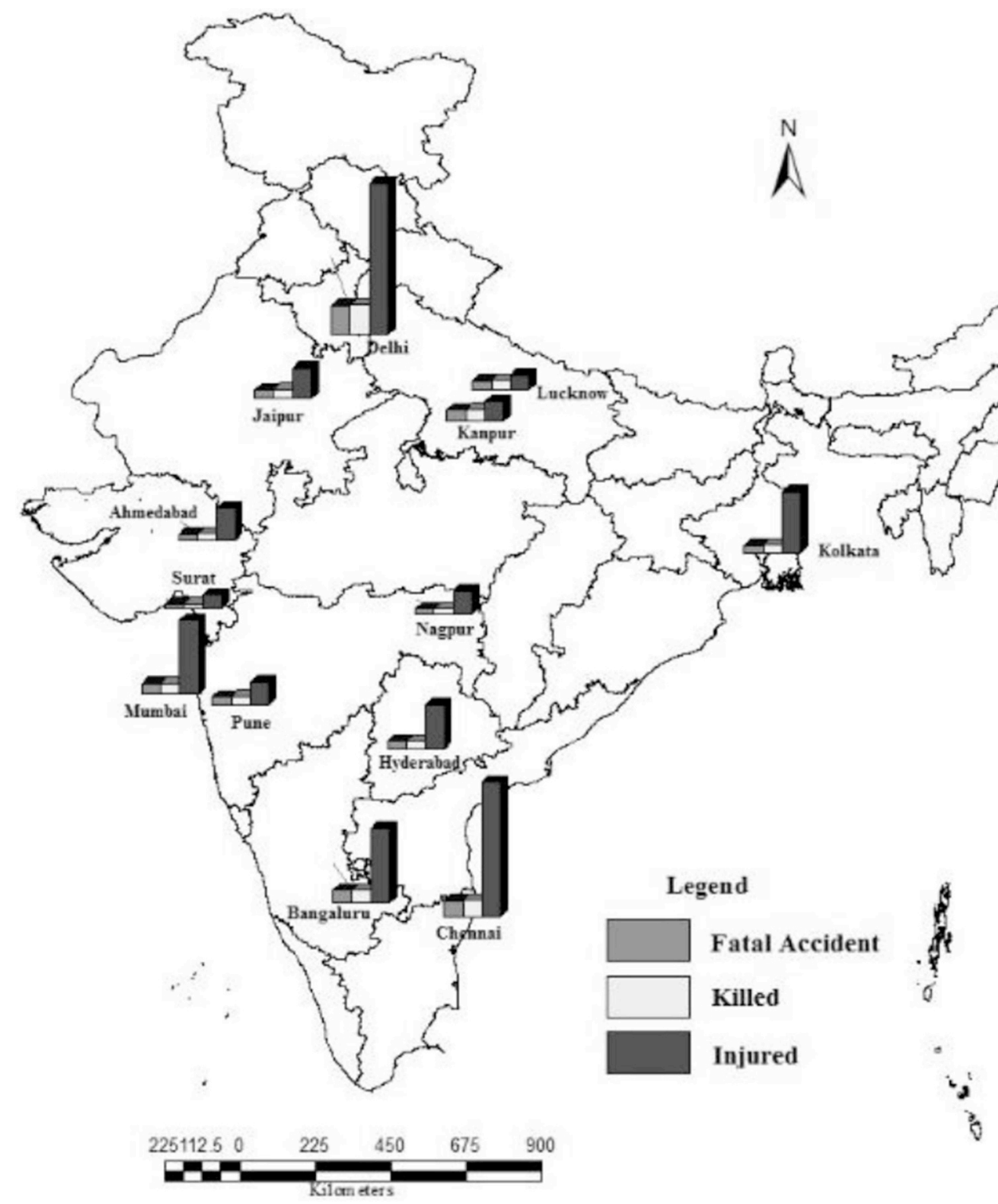

Map: 1. Map of India showing the location of selected 13 cities, and persons killed in RTAs, fatal accidents, and the persons injured, 2015

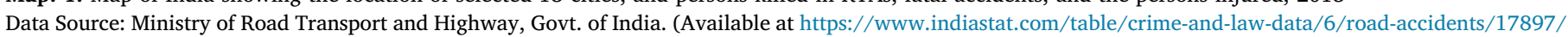
443689/data.aspx).

Table 1

Road Traffic Accidents in Indian cities by age-groups, 2015 (percentage)

\begin{tabular}{lllllll}
\hline \multirow{2}{*}{ Cities } & \multicolumn{2}{l}{ Age group } & & \multicolumn{3}{c}{ Total } \\
\cline { 2 - 6 } & $0-14$ & $14-30$ & $30-45$ & $45-60$ & $60+$ & \\
\hline Ahmedabad & 3 & 31 & 37 & 23 & 7 & 100 \\
Bengaluru & 2 & 37 & 31 & 23 & 8 & 100 \\
Chennai & 3 & 32 & 26 & 27 & 10 & 100 \\
Delhi & 2 & 42 & 37 & 15 & 4 & 100 \\
Hyderabad & 1 & 43 & 43 & 10 & 3 & 100 \\
Jaipur & 2 & 45 & 30 & 16 & 8 & 100 \\
Kanpur & 2 & 42 & 36 & 14 & 6 & 100 \\
Kolkata & 1 & 17 & 51 & 30 & 2 & 100 \\
Lucknow & 3 & 44 & 34 & 17 & 2 & 100 \\
Mumbai & 7 & 39 & 26 & 15 & 12 & 100 \\
Nagpur & 3 & 28 & 35 & 23 & 11 & 100 \\
Pune & 2 & 36 & 31 & 19 & 12 & 100 \\
Surat & 3 & 43 & 31 & 19 & 4 & 100 \\
\hline
\end{tabular}

Data Source: Ministry of Home Affairs, Govt. of India. (Available at https:// www.indiastat.com/table/crime-and-law-data/6/road-accidents/17897/ 1055844/data.aspx). control of traffic signal as well as adherence to traffic rule varies across the cities, which is resulting into the differences in the cite and time of RTAs. These indicate that any step or policy targeting to curb RTAs needs to be city specific.

Cities in India are quite different from each other. Some of the cities are disproportionately larger than others. As such, the road pattern, type of vehicles, type of major functions of a city, type of population etc. greatly varies from each other. Thus, there is no clear pattern of RTAs in Indian cities. Hence, there is a need for city-based strategies to reduce the RTAs, injuries, and deaths, under the big umbrella of related national policy.

\section{Funding}

Authors received no financial support to report.

\section{Conflicts of interest}

No conflict of interest exists among the authors. 
Table 2

Road Traffic Accidents in Indian cities by location, 2015 (in percentage)

\begin{tabular}{|c|c|c|c|c|c|c|c|c|}
\hline Cities & Near Residential Area & Near Religious Place & Near Cinema Hall & Near Factory/Industrial Area & At Pedestrian Crossing & Others & Rural Counter part & Total \\
\hline Ahmedabad & 36 & 5 & 3 & 11 & 10 & 34 & 0 & 100 \\
\hline Bengaluru & 15 & 7 & 9 & 9 & 13 & 45 & 2 & 100 \\
\hline Chennai & 2 & 2 & 4 & 3 & 13 & 47 & 29 & 100 \\
\hline Delhi & 15 & 2 & 0 & 2 & 7 & 71 & 2 & 100 \\
\hline Hyderabad & 19 & 4 & 7 & 1 & 21 & 48 & 0 & 100 \\
\hline Jaipur & 9 & 2 & 3 & 1 & 0 & 26 & 59 & 100 \\
\hline Kanpur & 27 & 2 & 1 & 12 & 2 & 17 & 39 & 100 \\
\hline Kolkata & 23 & 5 & 10 & 1 & 46 & 14 & 0 & 100 \\
\hline Lucknow & 27 & 0 & 1 & 7 & 0 & 9 & 56 & 100 \\
\hline Mumbai & 25 & 6 & 3 & 4 & 8 & 51 & 3 & 100 \\
\hline Nagpur & 14 & 1 & 0 & 2 & 6 & 62 & 15 & 100 \\
\hline Pune & 25 & 7 & 4 & 3 & 22 & 38 & 1 & 100 \\
\hline Surat & 48 & 3 & 2 & 20 & 7 & 9 & 11 & 100 \\
\hline
\end{tabular}

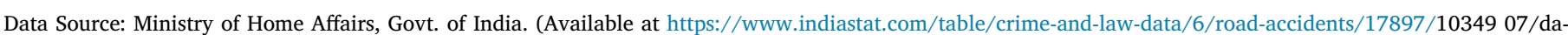
ta.aspx).

Table 3

Road Traffic Accidents in Indian cities by time of accident, 2015 (in percentage)

\begin{tabular}{|c|c|c|c|c|c|c|c|c|c|}
\hline \multirow[t]{2}{*}{ Cities } & $\begin{array}{l}00: 00 \mathrm{~h} \text { to } \\
03: 00 \mathrm{~h}\end{array}$ & $\begin{array}{l}03: 00 \mathrm{~h} \text { to } \\
06: 00 \mathrm{~h}\end{array}$ & $\begin{array}{l}06: 00 \mathrm{~h} \text { to } \\
09: 00 \mathrm{~h}\end{array}$ & $\begin{array}{l}09: 00 \mathrm{~h} \text { to } \\
12: 00 \mathrm{~h}\end{array}$ & $\begin{array}{l}12: 00 \mathrm{~h} \text { to } \\
15: 00 \mathrm{~h}\end{array}$ & $\begin{array}{l}15: 00 \mathrm{~h} \text { to } \\
18: 00 \mathrm{~h}\end{array}$ & $\begin{array}{l}18: 00 \mathrm{~h} \text { to } \\
21: 00 \mathrm{~h}\end{array}$ & $\begin{array}{l}21: 00 \mathrm{~h} \text { to } \\
24: 00 \mathrm{~h}\end{array}$ & \multirow[t]{2}{*}{ Total } \\
\hline & Night & Night & Day & Day & Day & Day & Night & Night & \\
\hline Ahmedabad & 6 & 3 & 13 & 18 & 14 & 14 & 16 & 15 & 100 \\
\hline Bengaluru & 4 & 6 & 13 & 16 & 16 & 17 & 17 & 12 & 100 \\
\hline Chennai & 4 & 5 & 12 & 16 & 15 & 16 & 19 & 14 & 100 \\
\hline Delhi & 10 & 9 & 11 & 11 & 12 & 14 & 16 & 17 & 100 \\
\hline Hyderabad & 8 & 6 & 11 & 14 & 15 & 16 & 15 & 15 & 100 \\
\hline Jaipur & 3 & 3 & 9 & 17 & 20 & 17 & 20 & 12 & 100 \\
\hline Kanpur & 15 & 14 & 13 & 9 & 12 & 13 & 14 & 9 & 100 \\
\hline Kolkata & 7 & 5 & 10 & 16 & 15 & 14 & 16 & 17 & 100 \\
\hline Lucknow & 6 & 9 & 17 & 15 & 14 & 12 & 16 & 12 & 100 \\
\hline Mumbai & 10 & 7 & 10 & 15 & 14 & 16 & 15 & 14 & 100 \\
\hline Nagpur & 4 & 4 & 8 & 16 & 16 & 16 & 20 & 16 & 100 \\
\hline Pune & 10 & 7 & 10 & 15 & 13 & 14 & 18 & 12 & 100 \\
\hline Surat & 6 & 2 & 9 & 16 & 18 & 12 & 20 & 17 & 100 \\
\hline
\end{tabular}

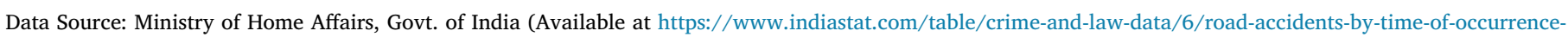
1998-2016/376211/1034542/data.aspx).

\section{Appendix A. Supplementary data}

Supplementary data to this article can be found online at https:// doi.org/10.1016/j.cegh.2019.01.005.

\section{References}

1. World Health Organization. Global Status Report on Road Safety 2015. WHO; 2015.

2. Government of India. Road Accidents in India 2015. New Delhi: Ministry of Road Transport \& Highways Transport Research Wingh; 2015.

3. Gururaj G, Gautham MS. Advancing Road Safety in India-Implementation Is the Key (Summary). Bengaluru: National Institute of Mental Health \& Neuro Sciences; 2017.

4. Kopits E, Cropper M. Traffic fatalities and economic growth. Accid Anal Prev. 2005;37:169-178.

5. Singh SK. Road traffic accidents in India: issues and challenges. Trans Res Procedia. 2017;25:4708-4719.

6. Kar S, Das SC, Tiwari A, Pharveen I. Pattern of road traffic accidents in Bhubaneswar, Odisha. Clin Epidemiol Glob Health. 2016;4:115-119.

7. Bhalla K, Khurana N, Bose D, Navaratne KV, Tiwari G, Mohan D. Official government statistics of road traffic deaths in India under-represent pedestrians and motorised two wheeler riders. Inj Prev. 2017;23:1-7. https://doi.org/10.1136/injuryprev-2016042053.

8. Rathi R. Road traffic accidents- burden on society. EC Orthopaedics. 2018;9.2:30-33. 9. Agrawal AK, Bishnoi M, Girishbhai PM, Vishnubhai PM, Pravinbhai PP, Vinodbhai PP. Epidemiological study on patients with road traffic accidents admitted in department of orthopaedics at a rural hospital in India (a retrospective study of more than 1000 patients). Int J Orthop Sci. 2018;4(1):23-26.

10. Goli S, Shruti, Siddiqui MZ, Gouda J. Road traffic accidents and injuries in India, high spending on hospitalised treatment. Econ Pol Wkly. 2018;LIII(14):52-60.

11. Sivakumar T, Krishnaraj R. Relationship between road traffic accidents and sociodemographic factors in India. Int J Pharmaceut Sci Rev Res. 2015;33(2):137-144.

12. Goel R. Modelling of road traffic fatalities in India. Accid Anal Prev. 2018;112:105-115.

13. Government of India. Ministry of Housing and Urban Affairs. http://mohua.gov.in/ $\mathrm{cms}$ /number-of-cities-towns-by-city-size-class.php. [Online] [Accessed: 1-9-2018.].

14. Morain SR, Gielen AC, Bhalla K. Automated speed enforcement systems to reduce traffic-related injuries: closing the policy implementation gap. Inj Prev. 2016;22(1):79-83.

15. Garg N, Hyder AA. Exploring the relationship between development and road traffic injuries: a case study from India. Eur J Public Health. 2006;16(5):487-491. 